Review Article

Yusheng Hu, Ziyun Yu, Genlian Fan*, Zhanqiu Tan, Jiandang Zhou, Hao Zhang, Zhiqiang Li, and Di Zhang

\title{
Simultaneous enhancement of strength and ductility with nano dispersoids in nano and ultrafine grain metals: a brief review
}

https://doi.org/10.1515/rams-2020-0028

Received Apr 01, 2020; accepted May 12, 2020

Abstract: Grain refinement is the most universal and effective method of strengthening metallic materials, which is known as the "Hall-Petch" relationship. However, when grain size is refined to sub-micro regime (Ultrafine Grain, UFG) or even nano regime (Nano Grain, NG), the plasticity of metallic materials becomes poor. Massive studies indicate that the low strain hardening ability resulted from the enhanced dynamic recovery and lack of dislocation accumulation in fine grains is the main reason for low ductility in UFG/NG metals. To resolve this "strength-ductility" conflict, different strategies have been taken, like bimodal/multimodal structure, nanotwins, gradient structure and intragranular nano dispersoids. Among them, the introduction of nano dispersoids into the fine grains attracted lots of attention due to its wide applicability and great success in simultaneously increasing the strength and ductility of the UFG/NG metal. In addition to the enhanced mechanical performance, the introduced secondphase particle may also bring some extraordinary functional properties into the metallic material. In this paper, a brief view of the strategies to improve ductility of the UFG/NG metals and the relevant toughening mechanisms are revealed. Special attentions are paid to the utilization of intragranular nano dispersoids in Aluminum alloys.

Keywords: strength-ductility, dislocation, strain hardening, ultrafine grains, nano dispersion method

\footnotetext{
${ }^{\star}$ Corresponding Author: Genlian Fan: State Key Laboratory of Metal Matrix Composites, School of Material Science and Engineering, Shanghai Jiao Tong University, Shanghai, 200240, China; Email: fangenlian@sjtu.edu.cn

Yusheng Hu: State Key Laboratory of Air-conditioning Equipment and System Energy Conservation, Zhuhai, 519070, China

Ziyun Yu, Zhanqiu Tan, Zhiqiang Li, Di Zhang: State Key Laboratory of Metal Matrix Composites, School of Material Science and Engineering, Shanghai Jiao Tong University, Shanghai, 200240, China
}

๖ Open Access. ๑ 2020 Y. Hu et al., published by De Gruyter. (cc) BY License

\section{Introduction}

Grain refinement has been proved to be most efficient method in strengthening metals for a long time. With the development of fabrication facilities and processing technologies, grain size of the metallic materials has been brought down to sub-micro regime (Ultrafine Grain, UFG, $100-1000 \mathrm{~nm}$ ) or even nano regime (Nano Grain, NG, $<100 \mathrm{~nm})$ and the strength were greatly enhanced [1-3]. However, the strength increase inevitably sacrifices ductility [4]. In order to resolve this "strength-ductility" conflict, special efforts have been paid. In the early studies, Koch [5] identified three major sources of limited ductility in UFG/NG metals: (1) artifacts from processing (e.g., pores); (2) force instability in tension; (3) crack nucleation or propagation instability. The latter two are closely related to the unique dislocation motion in the fine grains. Different theories and models have been proposed to reveal the plastic deformation behavior of UFG/NG metals, like pileup breakdown [6], grain-boundary dislocation creation and annihilation [7, 8], core and mantle models [9-11] and strain gradient models [12-15]. The combined effects of all the mentioned theories or models lead to one serious problem, the low strain hardening ability in UFG/NG metals.

Compared with the active dislocation interaction and high strain hardening rate in coarse grains, the dislocation accumulations are greatly reduced in UFGs and NGs, exhibiting a low strain hardening ability [16-18]. As is known to all, strain hardening ability is key to the stress transfer from the deformed to the undeformed grains, which plays an important role in stress distribution homogenization and early-stage defects prevention. Generally speaking, due to the size effect, dynamic recovery is enhanced in fine grains and the number of movable dislocations is greatly decreased. In most cases, single dislocation can

Jiandang Zhou, Hao Zhang: Jiangsu Haoran Spray Forming Alloy Co, Zhenjiang, 212003, China

This work is licensed under the Creative Commons Attribution 4.0 
glide through the whole grain without tangling with others [3] and the dislocation pile-up behavior [6] at grain boundary (GB) is also weakened.

The strain hardening rate $\theta$ can be expressed as [19]:

$$
\vartheta=\frac{1}{\sigma}\left(\frac{\partial \sigma}{\partial \epsilon}\right)_{\epsilon}
$$

Where $\sigma, \epsilon$ are the true stress and true strain respectively. According to Considère criteria, a critical stress is given when uniform elongation ends [20]:

$$
\sigma_{c}=\left(\frac{\partial \sigma}{\partial \epsilon}\right)_{\epsilon}
$$

Thus, a simple conclusion can be made from the equation (1-2) that metallic materials with higher strain hardening rate has larger uniform elongation and consequently better ductility. However, the poor strain hardening of UFG/NG metals always leads to local stress concentration and plastic instability. The early defects at the stressconcentrated regions will cause catastrophic shear fracture right after yielding with little uniform elongation [21].

In a word, the main reason for poor ductility in $\mathrm{UFG} / \mathrm{NG}$ metals is the lack of strain hardening, which is originated from the insufficient accumulation of dislocations in these fine grains. Some other factors including impurity concentration at GBs and reduced crack blunting effect of GBs in fine grains also deteriorate the ductility of UFG/NG materials [4].

\section{Strategies to improve the ductility of UFG/NG material}

First of all, due to the difficulty and complexity in producing consolidated UFG/NG metals, elimination of defects is always the primary goal for better overall mechanical performance [3, 5]. Defect-free UFG/NG metals with enhanced ductility have been reported [22, 23].

From the view of plastic deformation behavior, the primary task to improve the ductility of UFG/NG metals is to enhance the strain hardening ability through intragranular dislocation storage and promoted dislocation accumulation. Aimed on this, different strategies have been applied [24] and can be divided in to four categories. Firstly, bimodal [25] (multimodal [26]) and gradient structure [27] utilize the inhomogeneity of grain sizes, in which deformation mechanisms in both UFG/NG and coarse grains are simultaneously operative. Enhanced dislocation accumulation and extra strain hardening are found to be originated from the complex strain paths and triaxial strain components with very large strain gradient $[25,28,29]$. Secondly, nano twins (nano-sized internal interface) in fine grains can act as obstacles to dislocation motion and, thus, inhibit dislocation annihilation at grain boundaries. The complex reactions between dislocations and twin boundaries give rise to the intragranular dislocation storage [3032]. This strategy have been widely applied in nanostructured copper [30] and steel [33]. Pitifully, metals with high stacking fault energy, e.g. aluminum, are intrinsically incompatible with this novel strategy. Thirdly, transformation induced plasticity (TRIP) [34-36] or twinning induced plasticity (TWIP) $[37,38]$ can also be effective in UFG/NG metals. The underlying mechanisms remain the same with the traditional metallic material.

Apart from all the approaches mentioned above, the utilization of intragranular nano dispersoids is another effective and widely applied method. Dislocations are expected to be accumulated when confronting the nano dispersoids, which may lead to enhanced strain hardening and higher tensile ductility. What's more, due to the blocking effect of nano-dispersoids, the needed critical stress for dislocation slip will be raised and the metallic material is simultaneously strengthened. Therefore, introducing nano-dispersoids into UFG/NG metals is an effective strategy to simultaneously increase the ductility and strength. And it is suitable for nearly all kinds of metallic materials. Successful examples have already been reported in $\mathrm{Al}$ [3941], Mo [42] and steel [43-45], Mg [46], Cu [47], CoCrFeNiMn high entropy alloys [48], etc. The key to fully develop this unique strategy relies on the methods to introducing nano-dispersoids. In the following, the processing routes for utilization the intragranular nano dispersoids and the underlying mechanisms will be reviewed.

\section{Utilization of intragranular nano dispersoids}

To homogeneously introduce the nano particles, both insitu and ex-situ methods have been tried. To be simple, aluminum alloy or aluminum matrix composites were set as examples to elaborate the details of these methods.

\subsection{In-situ methods to introduce nano dispersoids}

The in-situ methods include nano-scale precipitation through thermo-mechanical treatment and introduction of nano particles (intermetallics, ceramic) through in-situ 
reaction. Zhao's group was the early one to use nanoscale precipitation to stengthen NG 7075 aluminum alloy [39]. The material was solution-treated to obtain a coarse-grained (CG) solid solution and was immediately cryogenically rolled to reduce the grain size with the final average of $100 \mathrm{~nm}$ (NS sample). The NS sample was then aged at low temperature to introduce very fine secondphase particles (NS+P sample). Due to the high dislocation density introduced during cryo-rolling, the precipitation behavior was prosperous and large amounts of nanodispersoids were formed, as shown in Figure 1(a). As indicated by the stress-strain curves in Figure 1(b), the tensile strength of NS sample is much higher than the CG sample, but its total elongation is very low. While the NS+P sample exhibit both higher strength and ductility compared with the NS sample. Higher-resolution electron microscopy (HREM) on NS+P samples in Figure 1(c-e) verified that the intragranular nano-dispersoids indeed blocked and accumulated dislocations. X-ray analysis on both NS and NS+P samples verified that the dislocation accumulation in $\mathrm{NS}+\mathrm{P}$ sample were much greater than the NS sample. The experimental results indicated the effectiveness of introducing nano-dispersoids in simultaneously improving the strength and ductility of UFG/NG metals. Similar success has been reported before and after Zhao's research $[44,49]$. But his study just used simple control experiments and demonstrated convinced evidence. Further work by Zhao using aged-hardening 2024 alloy showed better enhancement in ductility due to larger amounts of intragranular nano-dispersoids [50]. The incomplete dissolution of primary second-phase particles during solution treatment caused higher dislocation density after cryorolling and promoted precipitation during aging.

It should be noted that, the aging treatment needs to be elaborately designed. Both the location and the size of the precipitates should be well controlled to develop their blocking effect on dislocation slip. Intergranular and excessively large precipitates only have weak interaction with the dislocations, leading to low toughening efficiency. To avoid the unwanted precipitation, Sun's group has taken advantage of a microalloying strategy [51]. With trace Sc addition into the UFG Al-Cu alloys, a predominent intragranular precipitation was achieved, resulting in about $275 \%$ increment in ductility and simultaneously about $50 \%$ enhancement in yield strength by compared to its Sc-free counterpart where intergranular precipitation occurs even at room temperature. The minor addition of Sc is found to effectively stabilize the microstructure, strongly suppress the $\theta-\mathrm{Al}_{2} \mathrm{Cu}$ phase precipitation at grain boundary and remarkably promote the dispersion of $\theta^{\prime}-\mathrm{Al}_{2} \mathrm{Cu}$ nanoparticles in the grain interior in artificial aging. A sim- ilar microalloying strategy is expected to be equally effective for other UFG heat-treatable alloys such as Mg alloys and steel. This microalloying approach is simple and may be easily adapted to industrial processes.

Similar with the nano-scale precipitations, the in-situ reaction formed nanoparticles also showed great effectiveness. Generally, the in-situ nanoparticles can be formed via exothermic reaction. The related processing routes include reactive hot pressing [52], melt reaction [53-55], etc. Usually, secondary processing technique such as friction stir processing (FSP) is used for achieving a uniform distribution of reinforcing particles in matrix of the composites [56]. In situ $\left(\mathrm{Al}_{2} \mathrm{O}_{3}+\mathrm{Al}_{3} \mathrm{Zr}\right)_{n p} / \mathrm{Al}$ nanocomposites were successfully prepared by Zhao through magneto-chemical melt reaction from $\mathrm{Al}-\mathrm{Zr}\left(\mathrm{CO}_{3}\right)_{2}$ system [54]. The matrix grain size is about $400 \mathrm{~nm}$. The mean particle size is about $80 \mathrm{~nm}$, and the nanoparticles are well distributed in the $\mathrm{Al}$ matrix, as shown in Figure 2(a) [54]. The overall mechanical performance of the $\left(\mathrm{Al}_{2} \mathrm{O}_{3}+\mathrm{Al}_{3} \mathrm{Zr}\right)_{n p} / \mathrm{Al}$ nanocomposites are markedly higher than that of $\left(\mathrm{Al}_{2} \mathrm{O}_{3}+\mathrm{Al}_{3} \mathrm{Zr}\right)_{p} / \mathrm{Al}$ composites with micron-sized particles. The ultimate tensile strength increases from $80 \mathrm{MPa}$ to $320 \mathrm{MPa}$ and the total elongation rises from $\sim 10 \%$ to $\sim 20 \%$ with 8 vol $\%$ reinforcements. This significant strengthening and toughening effect was attributed to the pinning effect of the intragranular nanoparticles on dislocation motion, which was verified by the TEM image shown in Figure 2(b).

Similarly, Tian's group fabricated 2024Al matrix composites reinforced by the $\mathrm{ZrB}_{2}$ nano-particles from $2024 \mathrm{Al}-$ $\mathrm{K}_{2} \mathrm{ZrF}_{6}-\mathrm{KBF}_{4}$ system through melt in situ reaction [55]. The nanocomposites exhibited superior strength and ductility than the 2024 alloy matrix.

One thing needs to be mentioned is that the precipitation behavior in alloy and in-situ reaction is closely related to thermal process. So the thermal stability of the UFG/NG metals toughened by in-situ approaches is relatively poor. The already formed nano-dispersoids are relatively unstable and easy to grow into large sizes during the thermo-mechanical process, which may worsen the mechanical performance. Thus, the processing routes of insitu approaches should be elaborately modified to fully develop their toughening effect. New strategies like microalloying which can stabilize the fine microstructure at room temperature are well needed.

\subsection{Ex-situ methods to introduce nano dispersoids}

Apart from the in-situ nano-dispersoids formed through precipitation and reaction, nano ceramic or intermetallic 

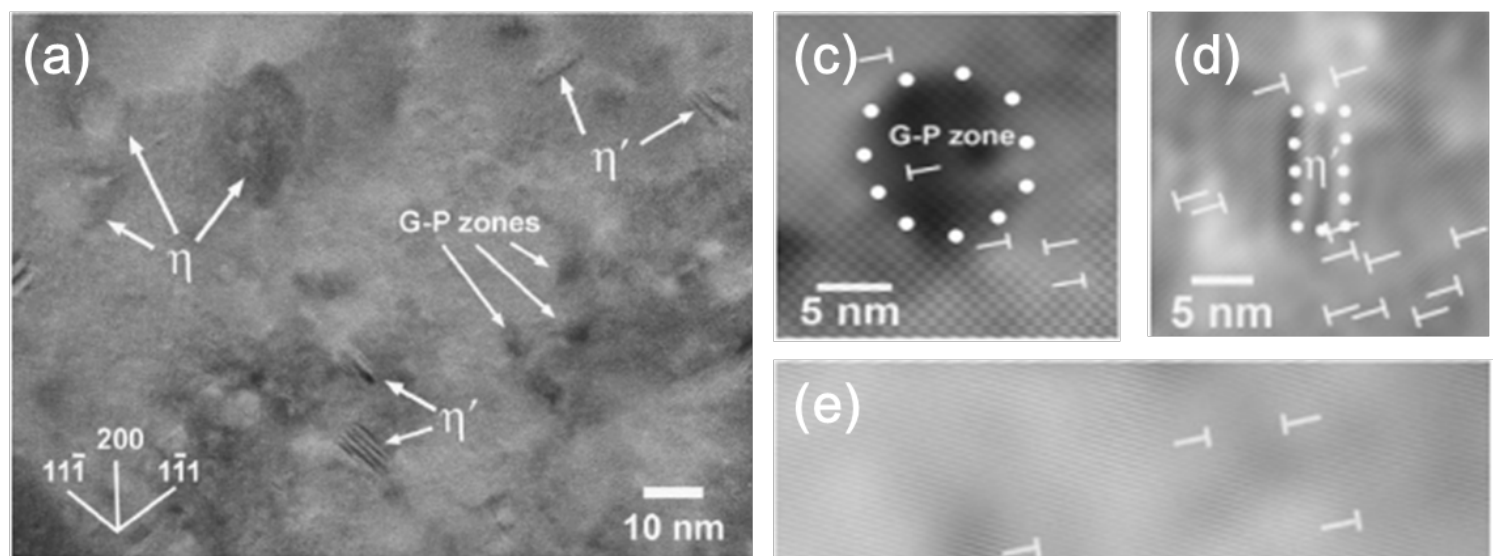

(b)
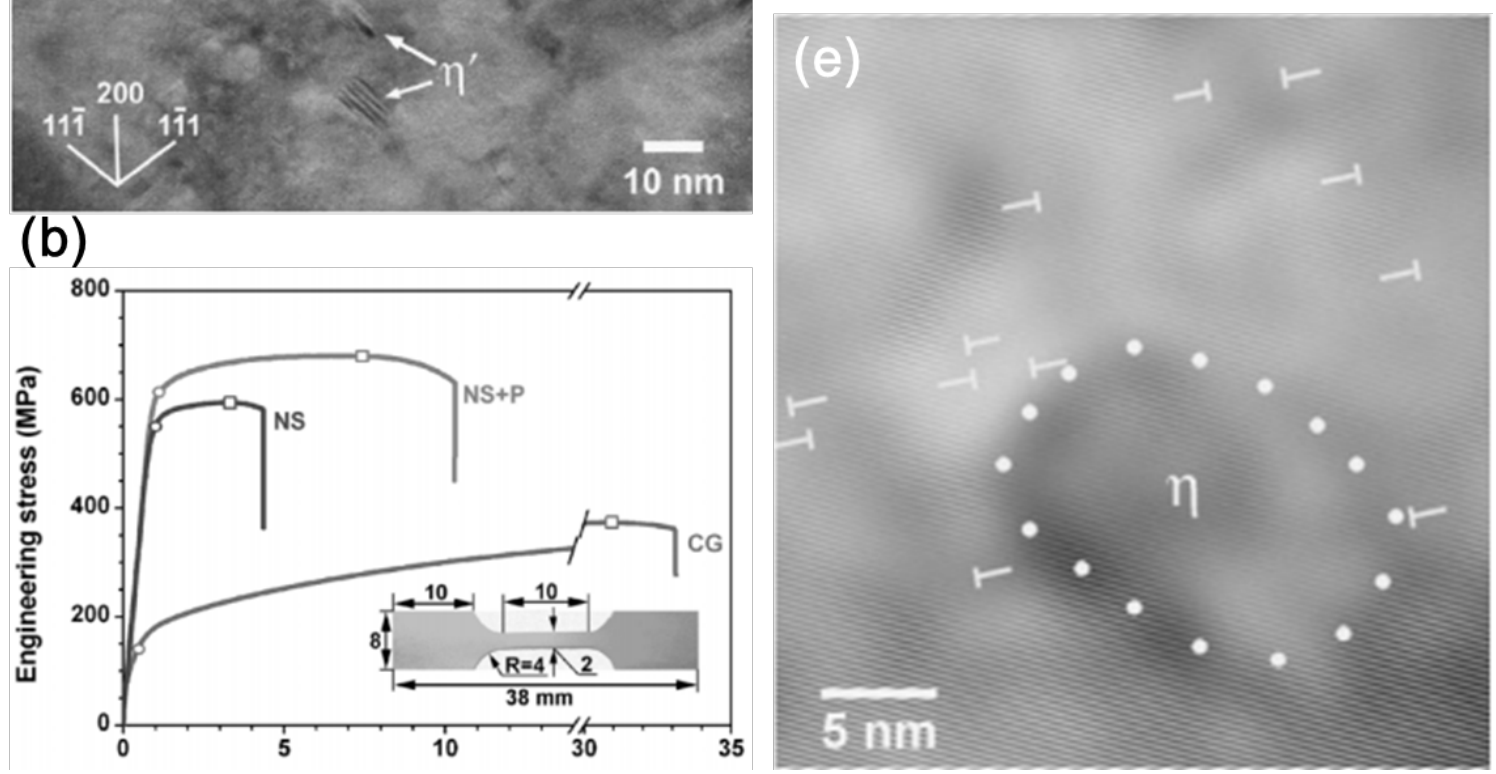

Figure 1: (a) prosperous precipitations in NS+P 7075 sample (b) Engineering stress-strain curves of the samples (c-e) 111 matrix planes obtained by inverse Fourier transformations of HRTEM images of an NS+P sample. White dots mark particle/matrix interface [39].
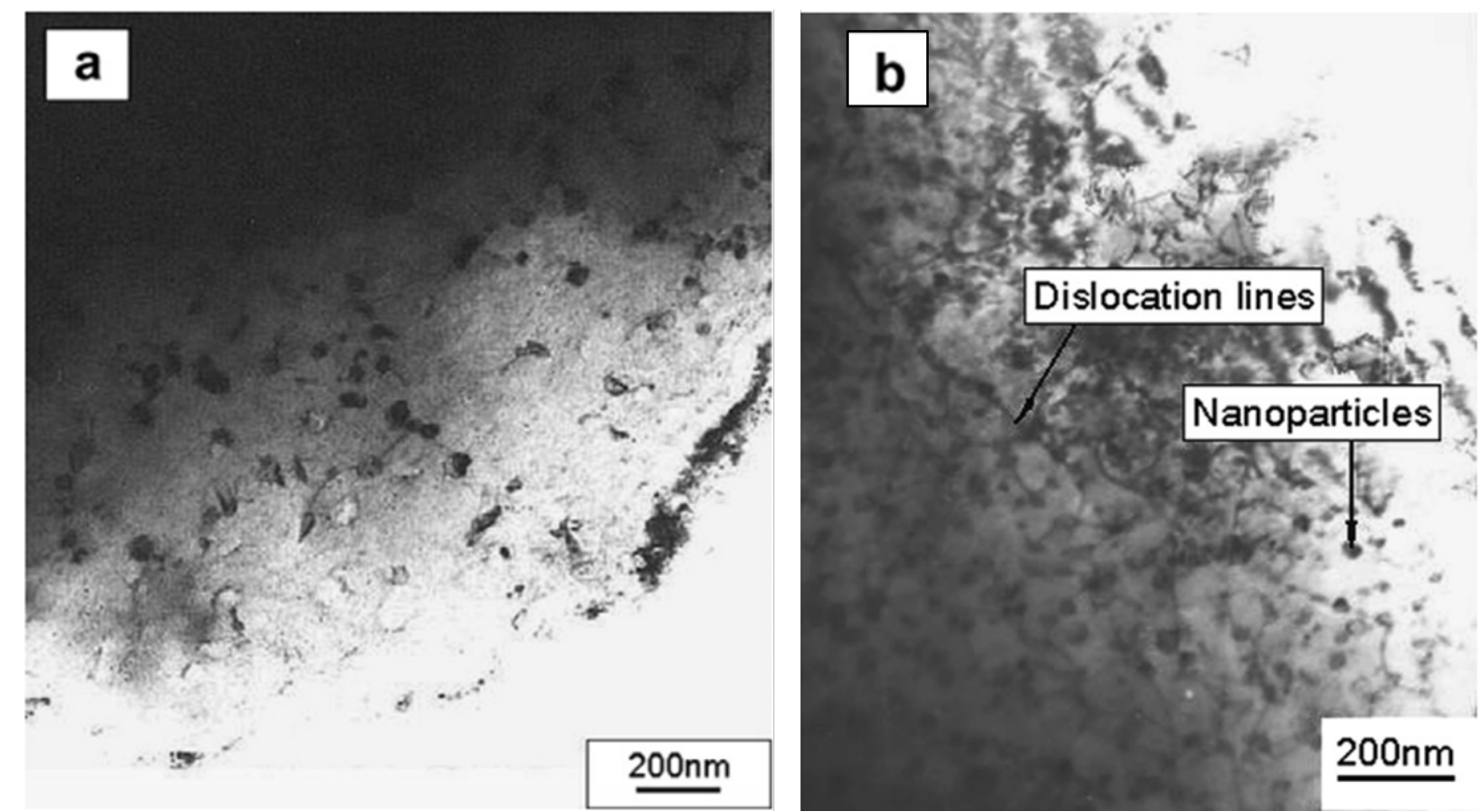

Figure 2: (a) the uniformly distributed $\mathrm{Al}_{2} \mathrm{O}_{3}+\mathrm{Al}_{3} \mathrm{Z}_{\mathrm{r}}$ nanodispersoids inside the grain (b) the pinned dislocations by the nanoparticles [54]. 
particles, such as alumina $\left(\mathrm{Al}_{2} \mathrm{O}_{3}\right)[19,57]$, silicon carbide (SiC) [58-60] and boron carbide $\left(\mathrm{B}_{4} \mathrm{C}\right)[61,62]$, have also been directly introduced into metal matrix as obstacles to dislocation slip, forming metal matrix nanocomposites (MMNCs). Previous studies indicate that the nanoparticles possess better mechanical performance and lower fracture sensitivity, making them ideal reinforcements [63-66]. What's more, the introduction of the reinforcing nanoparticles not only enhances the mechanical performance, but also brings in some exceptional functional property [6769], producing materials with integrated mechanical and functional performance. The main trouble in ex-situ approach is to break the agglomeration of nanoparticles and uniformly disperse them in the metal matrix. To solve this problem, various methods have been tried, like ultrasonication casting [70], squeeze casting [71] and powder metallurgy [72]. Generally speaking, due to the variation of density between metal melt and nanoparticles, it is difficult to uniformly disperse the tangled nanoparticles during liquid metallurgy process. Extra force like ultrasonication or squeeze is always needed to break the particle agglomeration. Compared to liquid processing, solid processing or powder metallurgy is well recognized as a potential method for achieving better dispersion of the nanoparticles in metal matrix. The impaction from milling ball and matrix plastic flow during consolidation process can well disperse the nanoparticles into metal matrix. And due to relatively lower fabrication temperature, the grain size is usually much smaller.

In Hu's work [19], the mixed aluminum powders with $15 \mathrm{wt} \% 30 \mathrm{~nm}$ alumina were cold compacted into a billet. Then FSP was employed to prepare the billets, which densify the compact and homogeneously distribute the nano alumina particles inside the grains, as shown in Figure 3(a). The as-produced $\mathrm{Al}_{2} \mathrm{O}_{3} / \mathrm{UFG} \mathrm{Al}$ composites (A1-A3) exhibited enhanced mechanical performance and much higher strain hardening rate compared with the UFG pure aluminum reported by $\mathrm{Yu}$ (P1-P3), as shown in Figure 3(c-d). The strengthening and toughening mechanisms are exactly the same as the in-situ precipitates, as verified by the TEM images presented in Figure 3(b).

A modified powder metallurgy technique called flake powder metallurgy (Flake PM) was employed to fabricate $\mathrm{B}_{4} \mathrm{C} / \mathrm{UFG} \mathrm{Al}\left(\mathrm{Al}_{2} \mathrm{O}_{3}\right)$ hierarchical nanocomposite [73], in which the native alumina on $\mathrm{Al}$ flake powder surface was broken and dispersed into UFG grain interior during processing. The microstructure of the nanocomposites is revealed in Figure 4(a-b) and the detailed processing route is shown in Figure 4(c). The as-produced $\mathrm{B}_{4} \mathrm{C} / \mathrm{UFG} \mathrm{Al}_{(}\left(\mathrm{Al}_{2} \mathrm{O}_{3}\right)$ possessed better mechanical performance (elongation of $\sim 8.9 \%$ and strength of $364 \mathrm{MPa}$ ) and higher strain hard- ening rate compared with the similar samples prepared by high energy ball milling (HEBM) and accumulative roll bonding (ARB).

In a related study by Jiang [74], the large specific area of the aluminum nanoflakes was believed to be conducive to the uniform dispersion of nano-sized reinforcements, such as carbon nanotubes. Compared with traditional high energy ball milling, Flake PM can achieve better dispersion and do less damage to reinforcements. The flexibility of Flake PM allow more elaborate control of material microstructure [75], which may lead to extra toughening effect. This newly developed technique can be widely applied to MMNCs with various kinds of reinforcements.

Different from the nano precipitates or reaction formed nano particles, the introduced ceramic or intermetallic nano dispersoids by ex-situ approach are relatively thermal stable. The size of the nano dispersoids can be well maintained during material fabrication and mechanical processing. Besides, the potential functional properties brought by the nanoparticles are very attractive in industry and national defense, such as structure stabilization of $\mathrm{Al}_{2} \mathrm{O}_{3}$ for high temperature alloy, irradiation absorption of $\mathrm{B}_{4} \mathrm{C}$ for nuclear application and heat conduction of $\mathrm{SiC}$ for thermal management.

Despite of the great advantage of MMNCs, efforts are still needed to fully release the potential of MMNCs. First, more works should be done for the homogeneous dispersion of the nanoparticles, which is the key to achieve good performance. Second, detailed research is needed in figuring out the effect of interfacial property (composition, orientation relationship, strength, etc) and interfacial behavior (interactions between dislocation and interface, evolution during processing) on overall mechanical and functional performance, which can guide the property design of the MMNCs. Jiang's research on $\mathrm{B}_{4} \mathrm{C}$ reinforced nanostrucutred aluminum sets an good example for the interface study [62]. Third, other than interface property, the effect of other microstructure features like particle size, particle inter-distance on the strain hardening rate and overall performance should be systematically studied. Design criteria should be drawn for the preparation of novel nano dispersoids reinforced MMNCs in the future.

\section{Conclusion and vista}

The key to improve the ductility of UFG/NG metals is enhancing its strain hardening ability through dislocation accumulation. Different strategies like bimodal/gradient structure, intragranular nano twins and nano dispersoids 

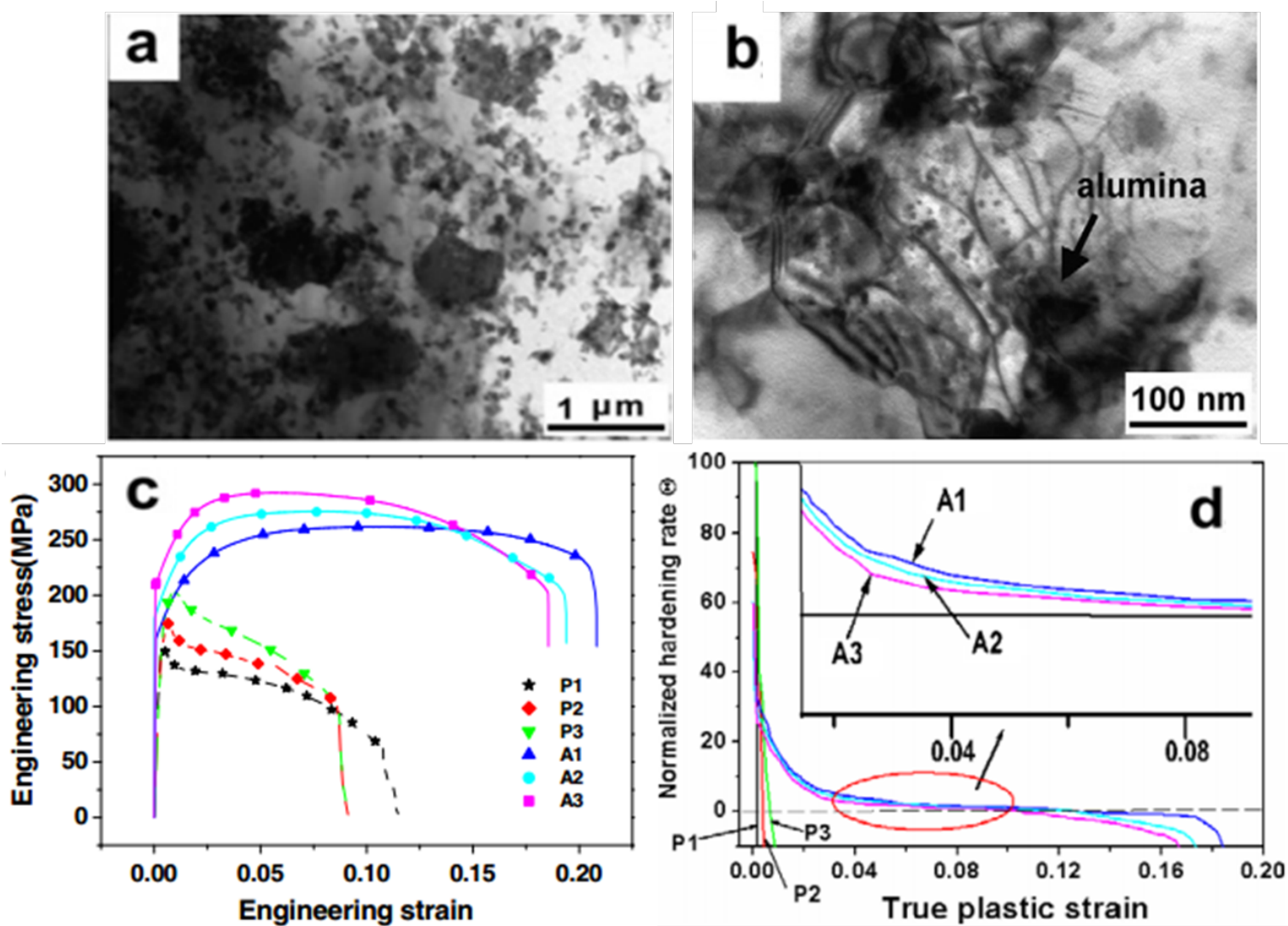

Figure 3: (a) the uniformly distributed alumina particles in aluminum matrix (b) the intensive interaction between alumina nanoparticles and dislocations ( $c-d)$ engineering stress-strain curves and normalized hardening rate of the as-produced $\mathrm{Al}_{2} \mathrm{O}_{3} / \mathrm{Al}_{\text {composites and the }}$ samples in other refs [19].
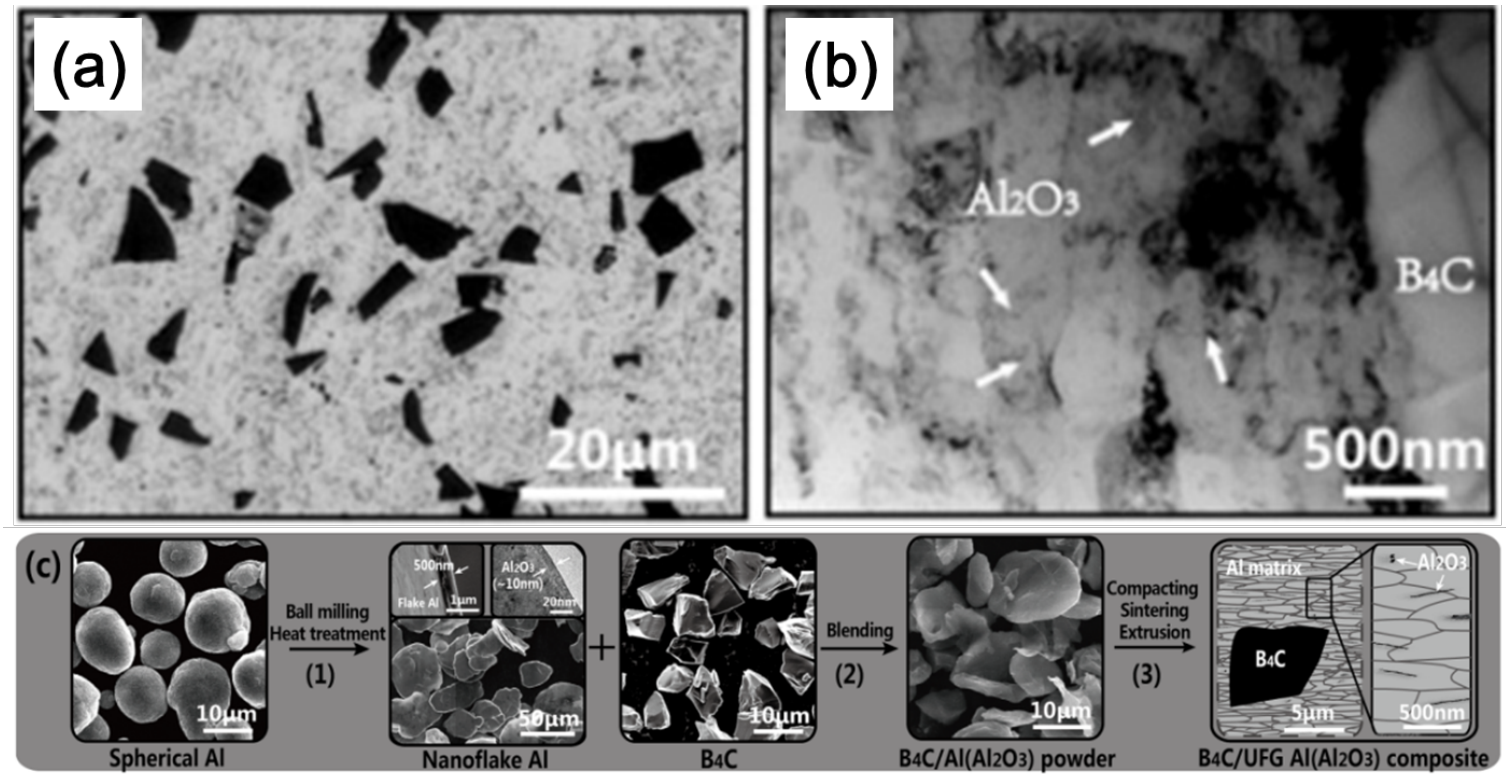

Figure 4: (a) SEM images of the $\mathrm{B}_{4} \mathrm{C} / \mathrm{UFG} \mathrm{Al}\left(\mathrm{Al}_{2} \mathrm{O}_{3}\right)$ nanocomposite showing the uniformly distributed micron-sized $\mathrm{B} 4 \mathrm{C}$ particles, (b) TEM images of the $\mathrm{B}_{4} \mathrm{C} / \mathrm{UFG} \mathrm{Al}\left(\mathrm{Al}_{2} \mathrm{O}_{3}\right)$ nanocomposite. The white arrows indicate the embedded $\mathrm{Al}_{2} \mathrm{O}_{3}$ nanoplatelets, (c) detailed processing route of the Flake PM [73]. 
all showed great effectiveness in toughening UFG/NG metals. Among them, the intragranular nano dispersoids strategy possesses relatively simple processing route and wider application. The main concern is how to homogeneously distribute the nanoparticles into grain interiors, more methods with high efficiency and homogeneity are required to be developed in future. The most attractive part in MMNCs is the outstanding functional properties brought by the nano dispersoids, which makes it possible to prepare UFG/NG metals with integrated mechanical and functional performance. Further studies should focus on exploring design criteria and optimizing the microstructure for these novel toughening strategies.

Acknowledgement: The authors would like to acknowledge the financial support from the National Key Research and Development Program of China (2017YFB1201105), the State Key Laboratory of Air-conditioning Equipment and System Energy Conservation (ACSKL2018KT15), the Natural Science Foundation of China (Nos. 51671130, 51871149), and Shanghai Science \& Technology Committee (19ZR1474900).

\section{References}

[1] Valiev, R. Nanostructuring of metals by severe plastic deformation for advanced properties. Nature Materials, Vol. 3, No. 8, 2004, pp. 511-516.

[2] Langdon, T. G. Twenty-five years of ultrafine-grained materials: Achieving exceptional properties through grain refinement. Acta Materialia, Vol. 61, No. 19, 2013, pp. 7035-7059.

[3] Meyers, M. A., A. Mishra, and D. J. Benson. Mechanical properties of nanocrystalline materials. Progress in Materials Science, Vol. 51, No. 4, 2006, pp. 427-556.

[4] Ma, E. Instabilities and ductility of nanocrystalline and ultrafinegrained metals. Scripta Materialia, Vol. 49, No. 7, 2003, pp. 663668.

[5] Koch, C. Optimization of strength and ductility in nanocrystalline and ultrafine grained metals. Scripta Materialia, Vol. 49, No. 7, 2003, pp. 657-662.

[6] Pande, C., R. Masumura, and R. Armstrong. Pile-up based HallPetch relation for nanoscale materials. Nanostructured Materials, Vol. 2, No. 3, 1993, pp. 323-331.

[7] Hasnaoui, A., P. Derlet, and H. Van Swygenhoven. Interaction between dislocations and grain boundaries under an indenter-a molecular dynamics simulation. Acta Materialia, Vol. 52, No. 8 , 2004, pp. 2251-2258.

[8] Van Swygenhoven, H., P. Derlet, and A. Frøseth. Nucleation and propagation of dislocations in nanocrystalline fcc metals. Acta Materialia, Vol. 54, No. 7, 2006, pp. 1975-1983.

[9] Benson, D. J., H.-H. Fu, and M. A. Meyers. On the effect of grain size on yield stress: Extension into nanocrystalline domain. Materials Science and Engineering A, Vol. 319, 2001, pp. 854-861.
[10] Fu, H.-H., D. J. Benson, and M. A. Meyers. Analytical and computational description of effect of grain size on yield stress of metals. Acta Materialia, Vol. 49, No. 13, 2001, pp. 2567-2582.

[11] Fu, H.-H., D. J. Benson, and M. A. Meyers. Computational description of nanocrystalline deformation based on crystal plasticity. Acta Materialia, Vol. 52, No. 15, 2004, pp. 4413-4425.

[12] Fleck, N., and J. Hutchinson. A phenomenological theory for strain gradient effects in plasticity. Journal of the Mechanics and Physics of Solids, Vol. 41, No. 12, 1993, pp. 1825-1857.

[13] Fleck, N., G. Muller, M. Ashby, and J. Hutchinson. Strain gradient plasticity: Theory and experiment. Acta Metallurgica et Materialia, Vol. 42, No. 2, 1994, pp. 475-487.

[14] Gao, H., Y. Huang, W. Nix, and J. Hutchinson. Mechanism-based strain gradient plasticity-I. Theory. Journal of the Mechanics and Physics of Solids, Vol. 47, No. 6, 1999, pp. 1239-1263.

[15] Huang, Y., Z. Xue, H. Gao, W. Nix, and Z. Xia. A study of microindentation hardness tests by mechanism-based strain gradient plasticity. Journal of Materials Research, Vol. 15, No. 08, 2000, pp. 1786-1796.

[16] Wang, Y., and E. Ma. Three strategies to achieve uniform tensile deformation in a nanostructured metal. Acta Materialia, Vol. 52, No. 6, 2004, pp. 1699-1709.

[17] Tsuji, N., Y. Ito, Y. Saito, and Y. Minamino. Strength and ductility of ultrafine grained aluminum and iron produced by ARB and annealing. Scripta Materialia, Vol. 47, No. 12, 2002, pp. 893899.

[18] Jia, D., Y. Wang, K. Ramesh, E. Ma, Y. Zhu, and R. Valiev. Deformation behavior and plastic instabilities of ultrafine-grained titanium. Applied Physics Letters, Vol. 79, No. 5, 2001, pp. 611613.

[19] Hu, C. M., C. M. Lai, X. H. Du, N. J. Ho, and J. C. Huang. Enhanced tensile plasticity in ultrafine-grained metallic composite fabricated by friction stir process. Scripta Materialia, Vol. 59, No. 11, 2008, pp. 1163-1166.

[20] Hart, E. W. Theory of the tensile test. Acta Metallurgica, Vol. 15, No. 2, 1967, pp. 351-355.

[21] Jia, D., K. Ramesh, and E. Ma. Effects of nanocrystalline and ultrafine grain sizes on constitutive behavior and shear bands in iron. Acta Materialia, Vol. 51, No. 12, 2003, pp. 3495-3509.

[22] Cheng, S., E. Ma, Y. Wang, L. Kecskes, K. Youssef, C. Koch, U. Trociewitz, and K. Han. Tensile properties of in situ consolidated nanocrystalline Cu. Acta Materialia, Vol. 53, No. 5, 2005, pp.15211533.

[23] Youssef, K. M., R. O. Scattergood, K. L. Murty, J. A. Horton, and C. C. Koch. Ultrahigh strength and high ductility of bulk nanocrystalline copper. Applied Physics Letters, Vol. 87, No. 9, 2005, p. 091904.

[24] Ma, E. Eight routes to improve the tensile ductility of bulk nanostructured metals and alloys. JOM, Vol. 58, No. 4, 2006, pp. 49-53.

[25] Wang, Y., M. Chen, F. Zhou, and E. Ma. High tensile ductility in a nanostructured metal. Nature, Vol. 419, No. 6910, 2002, pp. 912-915.

[26] Zhao, Y., T. Topping, J. F. Bingert, J. J. Thornton, A. M. Dangelewicz, Y. Li, et al. High tensile ductility and strength in bulk nanostructured nickel. Advanced Materials, Vol. 20, No. 16, 2008, pp. 3028-3033.

[27] Fang, T. H., W. L. Li, N. R. Tao, and K. Lu. Revealing extraordinary intrinsic tensile plasticity in gradient nano-grained copper. Science, Vol. 331, No. 6024, 2011, pp. 1587-1590. 
[28] Wu, X., P. Jiang, L. Chen, F. Yuan, and Y. T. Zhu. Extraordinary strain hardening by gradient structure. Proceedings of the $\mathrm{Na}$ tional Academy of Sciences of the United States of America, Vol. 111, No. 20, 2014, pp. 7197-7201.

[29] Wu, X., P. Jiang, L. Chen, J. Zhang, F. Yuan, and Y. Zhu. Synergetic strengthening by gradient structure. Materials Research Letters, Vol. 2, No. 4, 2014, pp. 185-191.

[30] Lu, L., Y. Shen, X. Chen, L. Qian, and K. Lu. Ultrahigh strength and high electrical conductivity in copper. Science, Vol. 304, No. 5669, 2004, pp. 422-426.

[31] Shen, Y., L. Lu, Q. Lu, Z. Jin, and K. Lu. Tensile properties of copper with nano-scale twins. Scripta Materialia, Vol. 52, No. 10, 2005 , pp. 989-994.

[32] Li, X., Y. Wei, L. Lu, K. Lu, and H. Gao. Dislocation nucleation governed softening and maximum strength in nano-twinned metals. Nature, Vol. 464, No. 7290, 2010, pp. 877-880.

[33] Yan, F., G. Liu, N. Tao, and K. Lu. Strength and ductility of 316L austenitic stainless steel strengthened by nano-scale twin bundles. Acta Materialia, Vol. 60, No. 3, 2012, pp. 1059-1071.

[34] Tao, K., H. Choo, H. Li, B. Clausen, J.-E. Jin, and Y.-K. Lee. Transformation-induced plasticity in an ultrafine-grained steel: An in situ neutron diffraction study. Applied Physics Letters, Vol. 90, No. 10, 2007, id. 101911.

[35] Cheng, S., H. Choo, Y. Zhao, X.-L. Wang, Y. Zhu, Y. Wang, et al. High ductility of ultrafine-grained steel via phase transformation. Journal of Materials Research, Vol. 23, No. 06, 2008, pp. 15781586.

[36] Ma, Y., J.-E. Jin, and Y.-K. Lee. A repetitive thermomechanical process to produce nano-crystalline in a metastable austenitic steel. Scripta Materialia, Vol. 52, No. 12, 2005, pp. 1311-1315.

[37] Rösner, H., J. Markmann, and J. Weissmüller. Deformation twinning in nanocrystalline Pd. Philosophical Magazine Letters, Vol. 84, No. 5, 2004, pp. 321-334.

[38] Dini, G., A. Najafizadeh, R. Ueji, and S. Monir-Vaghefi. Improved tensile properties of partially recrystallized submicron grained TWIP steel. Materials Letters, Vol. 64, No. 1, 2010, pp. 15-18.

[39] Zhao, Y.-H., X.-Z. Liao, S. Cheng, E. Ma, and Y. T. Zhu. Simultaneously increasing the ductility and strength of nanostructured alloys. Advanced Materials, Vol. 18, No. 17, 2006, pp. 2280-2283.

[40] Zan, Y. N., Y. T. Zhou, Z. Y. Liu, G. N. Ma, D. Wang, Q. Z. Wanget al. Enhancing strength and ductility synergy through heterogeneous structure design in nanoscale $\mathrm{Al}_{2} \mathrm{O}_{3}$ particulate reinforced $\mathrm{Al}$ composites. Materials \& Design, Vol. 166, 2019, p. 166.

[41] Balog, M., T. Hu, P. Krizik, M.V. Castro Riglos, B.D. Saller, H. Yang et al. On the thermal stability of ultrafine-grained Al stabilized by in-situ amorphous $\mathrm{Al}_{2} \mathrm{O}_{3}$ network. Materials Science and Engineering a-Structural Materials Properties Microstructure and Processing, Vol. 648, 2015, pp. 61-71.

[42] Liu, G., G. J. Zhang, F. Jiang, X. D. Ding, Y. J. Sun, J. Sun, et al. Nanostructured high-strength molybdenum alloys with unprecedented tensile ductility. Nature Materials, Vol. 12, No. 4, 2013 pp. 344-350.

[43] Lee, Y., J. Jin, and Y. Ma. Transformation-induced extraordinary ductility in an ultrafine-grained alloy with nanosized precipitates. Scripta Materialia, Vol. 57, No. 8, 2007, pp. 707-710.

[44] Tsuji, N., R. Ueji, Y. Minamino, and Y. Saito. A new and simple process to obtain nano-structured bulk low-carbon steel with superior mechanical property. Scripta Materialia, Vol. 46, No. 4, 2002, pp. 305-310.
[45] Lee, T., C. H. Park, D. L. Lee, and C. S. Lee. Enhancing tensile properties of ultrafine-grained medium-carbon steel utilizing fine carbides. Materials Science and Engineering a-Structural Materials Properties Microstructure and Processing. Vol. 528, No. 21, 2011, pp. 6558-6564.

[46] Zhu, Z. H., K. B. Nie, K. K. Deng, and J. G. Han. Fabrication of biodegradable magnesium matrix composite with ultrafine grains and high strength by adding $\mathrm{TiC}$ nanoparticles to $\mathrm{Mg}$ 1.12Ca-0.84Zn-0.23Mn (at.\%) alloy. Materials Science and Engineering C, Vol. 107, 2020, 110360-110360.

[47] Li, C., Y. Xie, D. Zhou, W. Zeng, J. Wang, J. Liang, et al. A novel way for fabricating ultrafine grained $\mathrm{Cu}-4.5$ vol\% $\mathrm{Al}_{2} \mathrm{O}_{3}$ composite with high strength and electrical conductivity. Materials Characterization, Vol. 155, 2019, id. 109775.

[48] Xie, Y., T. Xia, D. Zhou, Y. Luo, W. Zeng, Z. Zhang, et al. A novel nanostructure to achieve ultrahigh strength and good tensile ductility of a CoCrFeNiMn high entropy alloy. Nanoscale, Vol. 12, No. 9, 2020, pp. 5347-5352.

[49] Wang, X., B. Huang, L. Wang, and Y. Rong. Microstructure and mechanical properties of microalloyed high-strength transformation-induced plasticity steels. Metallurgical and Materials Transactions. A, Physical Metallurgy and Materials Science, Vol. 39, No. 1, 2008, pp. 1-7.

[50] Cheng, S., Y. Zhao, Y. Zhu, and E. Ma. Optimizing the strength and ductility of fine structured $2024 \mathrm{Al}$ alloy by nano-precipitation. Acta Materialia, Vol. 55, No. 17, 2007, pp. 5822-5832.

[51] Jiang, L., J. K. Li, P. M. Cheng, G. Liu, R. H. Wang, B. A. Chen, et al. Microalloying ultrafine grained Al alloys with enhanced ductility. Scientific Reports. Vol. 4, No. 1, 2014, id. 3605.

[52] Roy, D., S. Ghosh, A. Basumallick, and B. Basu. Preparation of Fealuminide reinforced in situ metal matrix composites by reactive hot pressing. Materials Science and Engineering A, Vol. 415, No. 1, 2006, pp. 202-206.

[53] Tu, J., N. Wang, Y. Yang, W. Qi, F. Liu, X. Zhang, et al. Preparation and properties of TiB 2 nanoparticle reinforced copper matrix composites by in situ processing. Materials Letters, Vol. 52, No. 6, 2002, pp. 448-452.

[54] Zhao, Y.-T., S.-L. Zhang, G. Chen, X.-N. Cheng, and C.-Q. Wang. In situ $\left(\mathrm{Al}_{2} \mathrm{O}_{3}+\mathrm{Al}_{3} \mathrm{Zr}\right) \mathrm{np} / \mathrm{Al}$ nanocomposites synthesized by magneto-chemical melt reaction. Composites Science and Technology, Vol. 68, No. 6, 2008, pp. 1463-1470.

[55] Tian, K., Y. Zhao, L. Jiao, S. Zhang, Z. Zhang, and X. Wu. Effects of in situ generated ZrB 2 nano-particles on microstructure and tensile properties of 2024Al matrix composites. Journal of Alloys and Compounds, Vol. 594, 2014, pp. 1-6.

[56] Zhang, Q., B. Xiao, Q. Wang, and Z. Ma. In situ Al3Ti and $\mathrm{Al}_{2} \mathrm{O}_{3}$ nanoparticles reinforced $\mathrm{Al}$ composites produced by friction stir processing in an Al-TiO2 system. Materials Letters, Vol. 65, No. 13, 2011, pp. 2070-2072.

[57] Mazahery, A., and M. Ostadshabani. Investigation on mechanical properties of nano- $\mathrm{Al}_{2} \mathrm{O}_{3}$-reinforced aluminum matrix composites. Journal of Composite Materials, Vol. 45, No. 24, 2011, pp. 2579-2586.

[58] Zhang, X., L. Geng, and G. Wang. Fabrication of Al-based hybrid composites reinforced with $\mathrm{SiC}$ whiskers and $\mathrm{SiC}$ nanoparticles by squeeze casting. Journal of Materials Processing Technology, Vol. 176, No. 1, 2006, pp. 146-151.

[59] Prasad Reddy, A., P. Vamsi Krishna, R. Narasimha Rao, and N. V. Murthy. Silicon Carbide Reinforced Aluminium Metal Matrix Nano Composites-A Review. Materials Today: Proceedings, Vol. 
4, No. 2, 2, Part A, 2017, pp. 3959-3971.

[60] Li, A. B., G. S. Wang, X. X. Zhang, Y. Q. Li, X. Gao, H. Sun, et al. Enhanced combination of strength and ductility in ultrafine-grained aluminum composites reinforced with high content intragranular nanoparticles. Materials Science and Engineering a-Structural Materials Properties Microstructure and Processing. Vol. 745, 2019, pp. 10-19.

[61] Zhang, Z., T. Topping, Y. Li, R. Vogt, Y. Zhou, C. Haines, J. Paras, D. Kapoor, J. M. Schoenung, and E. J. Lavernia. Mechanical behavior of ultrafine-grained Al composites reinforced with B4C nanoparticles. Scripta Materialia, Vol. 65, No. 8, 2011, pp. 652-655.

[62] Jiang, L., H. Wen, H. Yang, T. Hu, T. Topping, D. Zhang, et al. Influence of length-scales on spatial distribution and interfacial characteristics of $\mathrm{B} 4 \mathrm{C}$ in a nanostructured Al matrix. Acta Materialia, Vol. 89, 2015, pp. 327-343.

[63] Chawla, N., and Y.-L. Shen. Mechanical behavior of particle reinforced metal matrix composites. Advanced Engineering Materials, Vol. 3, No. 6, 2001, pp. 357-370.

[64] Qu, S., T. Siegmund, Y. Huang, P. Wu, F. Zhang, and K. Hwang. A study of particle size effect and interface fracture in aluminum alloy composite via an extended conventional theory of mechanism-based strain-gradient plasticity. Composites Science and Technology, Vol. 65, No. 7, 2005, pp. 1244-1253.

[65] Casati, R., and M. Vedani. Metal Matrix Composites Reinforced by Nano-Particles-A Review. Metals, Vol. 4, No. 1, 2014, pp. 65-83.

[66] Geng, R., F. Qiu, and Q.-C. Jiang. Reinforcement in Al Matrix Composites: A Review of Strengthening Behavior of Nano-Sized Particles. Advanced Engineering Materials, Vol. 20, No. 9, 2018, id. 1701089.

[67] Tu, J., W. Rong, S. Y. Guo, and Y. Yang. Dry sliding wear behavior of in situ $\mathrm{Cu}-\mathrm{TiB}_{2}$ nanocomposites against medium carbon steel. Wear, Vol. 255, No. 7, 2003, pp. 832-835.
[68] Gül, H., F. Kılıç, S. Aslan, A. Alp, and H. Akbulut. Characteristics of electro-co-deposited $\mathrm{Ni}-\mathrm{Al}_{2} \mathrm{O}_{3}$ nano-particle reinforced metal matrix composite (MMC) coatings. Wear, Vol. 267, No. 5, 2009, pp. 976-990.

[69] Kireitseu, M., D. Hui, and G. Tomlinson. Advanced shockresistant and vibration damping of nanoparticle-reinforced composite material. Composites. Part B, Engineering, Vol. 39, No. 1, 2008, pp. 128-138.

[70] Yang, Y., J. Lan, and X. Li. Study on bulk aluminum matrix nanocomposite fabricated by ultrasonic dispersion of nano-sized SiC particles in molten aluminum alloy. Materials Science and Engineering A, Vol. 380, No. 1, 2004, pp. 378-383.

[71] Kannan, C., and R. Ramanujam. Comparative study on the mechanical and microstructural characterisation of AA 7075 nano and hybrid nanocomposites produced by stir and squeeze casting. Journal of Advanced Research, Vol. 8, No. 4, 2017, pp. 309319.

[72] Suryanarayana, C., and N. Al-Aqeeli. Mechanically alloyed nanocomposites. Progress in Materials Science, Vol. 58, No. 4, 2013, pp. 383-502.

[73] Kai, X., Z. Li, G. Fan, Q. Guo, Z. Tan, W. Zhang, et al. Strong and ductile particulate reinforced ultrafine-grained metallic composites fabricated by flake powder metallurgy. Scripta Materialia, Vol. 68, No. 8, 2013, pp. 555-558.

[74] Jiang, L., Z. Li, G. Fan, L. Cao, and D. Zhang. The use of flake powder metallurgy to produce carbon nanotube (CNT)/aluminum composites with a homogenous CNT distribution. Carbon, Vol. 50, No. 5, 2012, pp. 1993-1998.

[75] Xu, R., Z. Tan, G. Fan, G. Ji, D.-B. Xiong, Q. Guo, et al. High-strength CNT/Al-Zn-Mg-Cu composites with improved ductility achieved by flake powder metallurgy via elemental alloying. Composites Part a-Applied Science and Manufacturing, Vol. 111, 2018, pp. 1-11. 